\title{
Comparative investigation of hydrogen bonding in silicon based PECVD grown dielectrics for optical waveguides
}

\author{
F. Ay, A. Aydinli * \\ Department of Physics, Bilkent University, 06800 Ankara, Turkey
}

Received 15 April 2003; received in revised form 25 November 2003; accepted 5 December 2003

Available online 22 January 2004

\begin{abstract}
Silicon oxide, silicon nitride and silicon oxynitride layers were grown by a PECVD technique. The resulting refractive indices of the layers varied between 1.47 and 1.93. The compositional properties of the layers were analyzed by FTIR and ATR infrared spectroscopy techniques. Comparative investigation of bonding structures for the three different layers was performed. Special attention was given to analyze $\mathrm{N}-\mathrm{H}$ bond stretching absorption at $3300-3400 \mathrm{~cm}^{-1}$. Quantitative results for hydrogen related bonding concentrations are presented based on IR analysis. An annealing study was performed in order to reduce or eliminate this bonding types. For the annealed samples the $\mathrm{N}-\mathrm{H}$ bond concentration was strongly reduced as verified by FTIR transmittance and ATR spectroscopic methods. A correlation between the $\mathrm{N}-\mathrm{H}$ concentration and absorption loss was verified for silicon oxynitride slab waveguides. Moreover, a single mode waveguide with silicon oxynitride core layer was fabricated. Its absorption and insertion loss values were determined by butt-coupling method, resulting in low loss waveguides.
\end{abstract}

(c) 2004 Elsevier B.V. All rights reserved.

\section{Introduction}

In recent years, growing attention has been paid to silicon based dielectrics such as silicon oxides, nitrides, and oxynitrides as potential materials for integrated optics [1-5]. This attention has been motivated mainly by their promising optical properties such as low absorption losses in the visible and near infrared. Moreover, the dielectric properties of $\mathrm{SiO}_{2}$ and the good chemical inertness and low permeability of $\mathrm{Si}_{3} \mathrm{~N}_{4}$ can be combined together to obtain silicon oxynitride ( $\mathrm{SiON}$ ) layers with desired properties. The index of refraction of these silicon based amorphous layers can easily be adjusted continuously over a wide range between 1.45 $\left(\mathrm{SiO}_{2}\right)$ and $2.0\left(\mathrm{Si}_{3} \mathrm{~N}_{4}\right)$, which comes to be very attractive property that allows fabrication of waveguides with desired characteristics of fiber match and compactness $[6,7]$. The growth of these layers can be done by well

\footnotetext{
${ }^{*}$ Corresponding author. Tel.: +90-312-290-1579; fax: +90-312-2664579.

E-mail address: aydinli@fen.bilkent.edu.tr (A. Aydinli).
}

established standard silicon integrated circuit processing tools, such as plasma enhanced chemical vapor deposition (PECVD) or low pressure chemical vapor deposition (LPCVD) techniques, which is also a key point for low cost mass production [8].

The major problem for integrated optics applications in the CVD grown silicon based layers has been reported to be the incorporation of hydrogen in the form of $\mathrm{N}-\mathrm{H}$ bonds into the film matrix $[9,10]$. Although there has been considerable number of both compositional and device related studies on the above mentioned dielectric films separately, there is a lack of systematic analysis comprising all three silicon based layers [11,12]. Namely, the dependence of the optical properties on film composition and growth parameters should be established for the whole range of compositions starting from silicon oxide and ending with silicon nitride films. In this study, an attempt is made to establish such a relation, to identify possible drawbacks of the films in the mentioned range and to possibly eliminate them, in a systematic way for the first time. In the following sections the deposition, material characterization, their 
treatment towards loss minimization, and finally the fabrication and characterization of single-mode waveguides are described.

\section{Experimental}

The silicon oxide $\left(\mathrm{SiO}_{x}\right)$, silicon nitride $\left(\mathrm{SiN}_{x}\right)$, and silicon oxynitride $\left(\mathrm{SiO}_{x} \mathrm{~N}_{y}\right.$ or $\mathrm{SiON}$ for short) layers were deposited in a parallel-plate type Plasmalab 8510C PECVD reactor. The layers were grown at 250 or 350 ${ }^{\circ} \mathrm{C}, 1$ Torr pressure at an RF power of $10 \mathrm{~W}$ with 13.56 $\mathrm{MHz}$ frequency applied to plates of diameter of $24 \mathrm{~cm}$. Silane $\left(2 \% \mathrm{SiH}_{4} / \mathrm{N}_{2}\right)$ gas flow rate was kept constant at $180 \mathrm{sccm}$, for all the samples. Nitrous oxide $\left(\mathrm{N}_{2} \mathrm{O}\right)$ was used in the deposition of all the three types of the films with varying flow rates and different ammonia $\left(\mathrm{NH}_{3}\right)$ flow rates were used in the growth of silicon nitride and oxynitride layers. The details of the growth parameters are given in Table 1.

The index of refraction and thickness of the grown films were measured by an automated Rudolph Research/AutoEl III ellipsometer at a wavelength of 632.8 $\mathrm{nm}$. Typical accuracy values of the measurements were \pm 0.01 and $\pm 20 \AA$ for the index of refraction and thickness of the films, respectively. In addition, the thickness values of some of the layers were measured by Sloan Dektak 3030ST stylus profilometer.

The compositional and structural properties of the grown layers were analyzed by making use of Bomem H\&B Series Fourier transform infrared (FTIR) spectrometer. The obtained spectra were in the 5500-250 $\mathrm{cm}^{-1}$ range with $8 \mathrm{~cm}^{-1}$ resolution and 1024 number of scans.

\section{Results and discussion}

\subsection{Refractive index and growth rate characterization}

Due to hydrogen and nitrogen incorporation into the film, the stoichiometry of the PECVD grown layers in general deviates from $\mathrm{SiO}_{2}$ and $\mathrm{Si}_{3} \mathrm{~N}_{4}$ taking the form of $\mathrm{SiO}_{x}$ and $\mathrm{SiN}_{x}$, respectively. Moreover, their index of refraction is expected to vary with the growth parameters. The samples analyzed in this section were grown typically on $10 \times 20 \mathrm{~mm}$ sized silicon substrates. The

Table 1

Growth parameters for silicon oxide, nitride, and oxynitride films

\begin{tabular}{lllll}
\hline Film type & \multicolumn{3}{c}{ Gas flow rates $(\mathrm{sccm})$} & \multirow{2}{\text{Temperature}}{$\left({ }^{\circ} \mathrm{C}\right)$} \\
\cline { 2 - 4 } & $\mathrm{SiH}_{4}$ & $\mathrm{~N}_{2} \mathrm{O}$ & $\mathrm{NH}_{3}$ & \\
\hline $\mathrm{SiO}_{x}$ & 180 & $25-300$ & 0 & 250,350 \\
$\mathrm{SiO}_{x} \mathrm{~N}_{y}$ & 180 & $20-450$ & 15,30 & 350 \\
$\mathrm{SiN}_{x}$ & 180 & 0 & $5-45$ & 350 \\
\hline
\end{tabular}

process parameters mentioned in Section 2 and given in Table 1 were used. The refractive index variation obtained for the $\mathrm{SiO}_{x}, \mathrm{SiN}_{x}$, and $\mathrm{SiO}_{x} \mathrm{~N}_{y}$ layers are given in Fig. 1. The corresponding film growth rate dependence on the $\mathrm{N}_{2} \mathrm{O}$ flow rate are depicted in Fig. 2.

As seen from Fig. 1, the values of the refractive index of both silicon oxide films, grown at 250 and $350{ }^{\circ} \mathrm{C}$, decrease from a value of about 1.56 down to 1.47 with
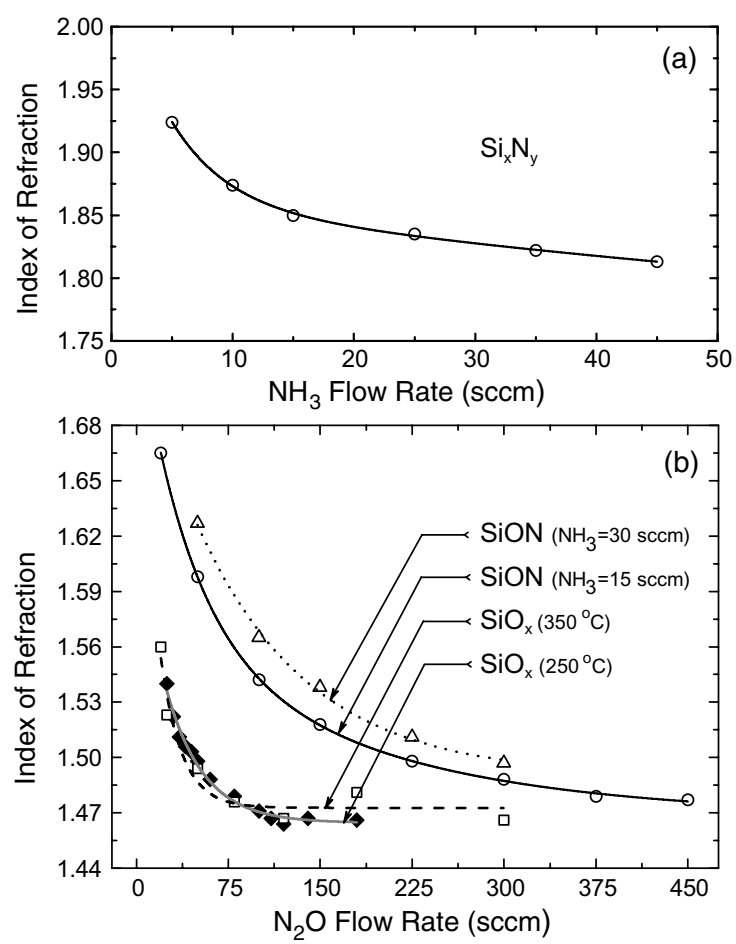

Fig. 1. Refractive index variation of $\mathrm{SiN}$ (a), $\mathrm{SiO}$ and $\mathrm{SiON}$ (b) films as a function of $\mathrm{N}_{2} \mathrm{O}$ and $\mathrm{NH}_{3}$ precursor gas flow rates.

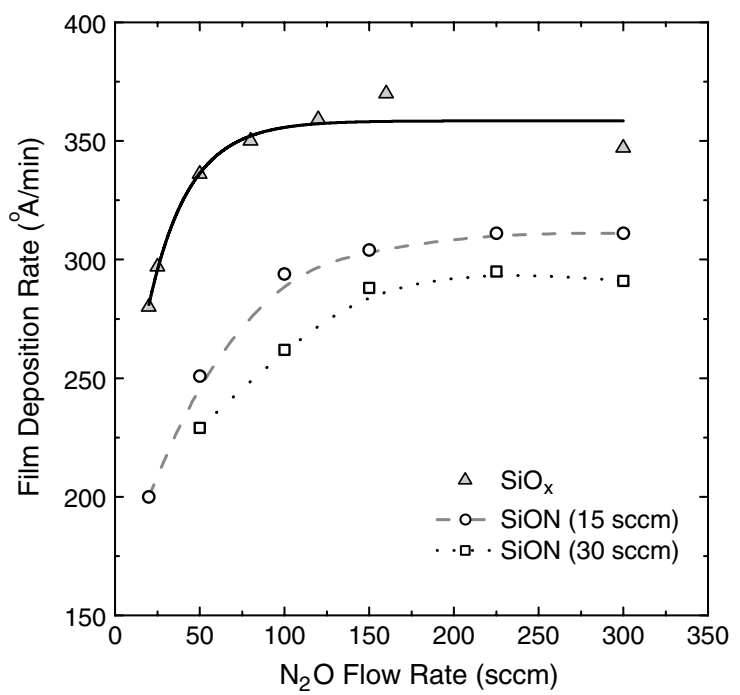

Fig. 2. Variation of film deposition rate for silicon oxide and silicon oxynitride films as a function of $\mathrm{N}_{2} \mathrm{O}$ and $\mathrm{NH}_{3}$ flow rates. 
increasing $\mathrm{N}_{2} \mathrm{O}$ flow rate. At $\mathrm{N}_{2} \mathrm{O}$ flow rates higher than $150 \mathrm{sccm}$ the decrease in the refractive index saturates. The high index region in Fig. 1 is due to silicon rich films. As the $\mathrm{N}_{2} \mathrm{O}$ flow increases large amount of oxygen and some nitrogen is incorporated into the films, resulting in refractive index closer to that of stoichiometric $\mathrm{SiO}_{2}$. The silicon oxide characterizations were performed at two different growth temperatures of 250 and $350{ }^{\circ} \mathrm{C}$ in order to compare the qualities of the films grown. It was observed that the growth rate decreases slowly as the substrate temperature is increased. For $\mathrm{N}_{2} \mathrm{O}$ flow of $25 \mathrm{sccm}$, the growth rate at $250{ }^{\circ} \mathrm{C}$ is $340 \AA$ / min, whereas at $350^{\circ} \mathrm{C}$ it decreases down to $290 \AA / \mathrm{min}$. This can be regarded as an indication that the films grown at higher temperatures are denser and contain less microvoids, which was also verified by monitoring the wet chemical etch rates of these layers. It is well known that etch rates obtained with chemical etch are smaller for denser $\mathrm{SiO}_{x}$ films. Therefore, the temperature of $350^{\circ} \mathrm{C}$ was chosen for the growth of silicon nitride and silicon oxynitride films in order to obtain films suitable for optical applications. Moreover, the hydrogen incorporation into the layer is reported to be less at higher deposition temperatures [13].

The silicon nitride layers were deposited by changing the flow rate of $\mathrm{NH}_{3}$ and keeping that of silane constant (see Table 1). The films were deposited for $30 \mathrm{~min}$ with the resulting film thicknesses having values between $\sim 2800$ and $\sim 3100 \AA$. A steady trend of decreasing growth rate with increasing $\mathrm{NH}_{3}$ flow between 120 and $95 \AA / m i n$ was observed. The resulting refractive index values ranged between 1.93 and 1.82 (see Fig. 1(a)). For $\mathrm{Si}_{x} \mathrm{~N}_{y}$ films, the index of refraction is higher at low $\mathrm{NH}_{3}$ concentration since the layers are silicon rich and decreases with increasing $\mathrm{NH}_{3}$ flow due to the increase in the amount of nitrogen and hydrogen incorporated in the layers.

Silicon oxynitride films were grown using silane, ammonia, and nitrous oxide as reactant gases. The process parameters were as specified in Table 1. The depositions were done by varying the $\mathrm{N}_{2} \mathrm{O}$ flow rate and keeping that of $\mathrm{NH}_{3}$ fixed at two different values. The refractive index of the grown $\mathrm{SiON}$ layers could be varied between 1.93 and 1.47. A general trend of decreasing refractive index with increasing $\mathrm{N}_{2} \mathrm{O}$ ratio was observed in all cases (see Fig. 1(b)), which comes about because of oxygen's greater chemical reactivity compared to nitrogen. In addition, as the flow rate of ammonia was increased, the film index increased due to their higher nitrogen content, thus gaining more resemblance with the silicon nitride layers. It was found that increasing the nitrous oxide flow rate results in an increase of film growth rate as well (see Fig. 2). Moreover, the deposition rate was observed to be decreasing with increasing ammonia flow rate. These properties are also attributed to the oxygen's greater affinity for reacting with silicon [14]. The decrease of the growth rate with increase in nitrogen concentration in the film can be explained by increasing probability of the nitrogen related bonding so that nitrogen's concentration in the film increases. Thus, the layers become more silicon nitride-like film, the growth rate of which is smaller than that of silicon oxide films. In fact, if we consider the growth rates for these films they increase in the following order: silicon nitride, silicon oxynitride, silicon oxide, exhibiting a smooth transition of the physical properties of silicon oxynitride from those of silicon oxide to silicon nitride.

\subsection{FTIR characterization}

Fourier transform infrared spectroscopy was used as a nondestructive technique to obtain direct information about the compositional properties of the grown layers, the types of chemical bonds present, and their impurity content and concentration. In the spectra obtained from the grown films, the spectral positions of the absorption bands correspond to the vibrational frequencies of the molecular species present in the films, their intensity to the concentration of such species. Moreover, the width of the observed peaks may give information about different atomic arrangements surrounding the bonds.

\subsection{1. $\mathrm{SiO}$ films}

The silicon oxide layers deposited for FTIR characterization were of thicknesses of about $\sim 6000 \AA$ with the same growth parameters as in Table 1. Four samples were used to monitor the compositional characteristics of the films. Namely, samples sio1, sio2, sio3, and sio4 with the corresponding $\mathrm{N}_{2} \mathrm{O}$ flow rates of $25,50,120$, and $300 \mathrm{sccm}$, respectively. The absorbance spectra of the samples are shown in Fig. 3(a). In the figure, the observed vibrational modes are enumerated and identified as given in Table 2.

All the samples show a dominant absorption feature around $1050 \mathrm{~cm}^{-1}$ which can be resolved into symmetric and asymmetric stretching vibrations of $\mathrm{Si}-\mathrm{O}$ groups. $\mathrm{Si}-\mathrm{O}$ rocking vibration is also common to all the samples and is observed at $\sim 450 \mathrm{~cm}^{-1}$. While the $\mathrm{Si}-\mathrm{O}$ rocking vibrational frequency is constant, the $\mathrm{Si}-\mathrm{O}$ symmetric stretching vibration shifts steadily to higher frequencies from 1026 to $1055 \mathrm{~cm}^{-1}$ as the flow rate of $\mathrm{N}_{2} \mathrm{O}$ increases. This could be attributed to the fact that, as the oxygen concentration in the film increases, the resemblance with stoichiometric $\mathrm{SiO}_{2}$ increases, whose corresponding band is at $1080 \mathrm{~cm}^{-1}$ [15-17]. Another feature that should be mentioned is the variation of the $\mathrm{Si}-\mathrm{H}$ symmetric stretching vibration for the samples under consideration. This vibration was detected around $2260 \mathrm{~cm}^{-1}$ for samples sio 1 and sio 2 only, while the $\mathrm{Si}-$ $\mathrm{H}$ bending vibration was observable only for sample sio1. Moreover, for sample sio1, the $\mathrm{Si}-\mathrm{O}$ bending 

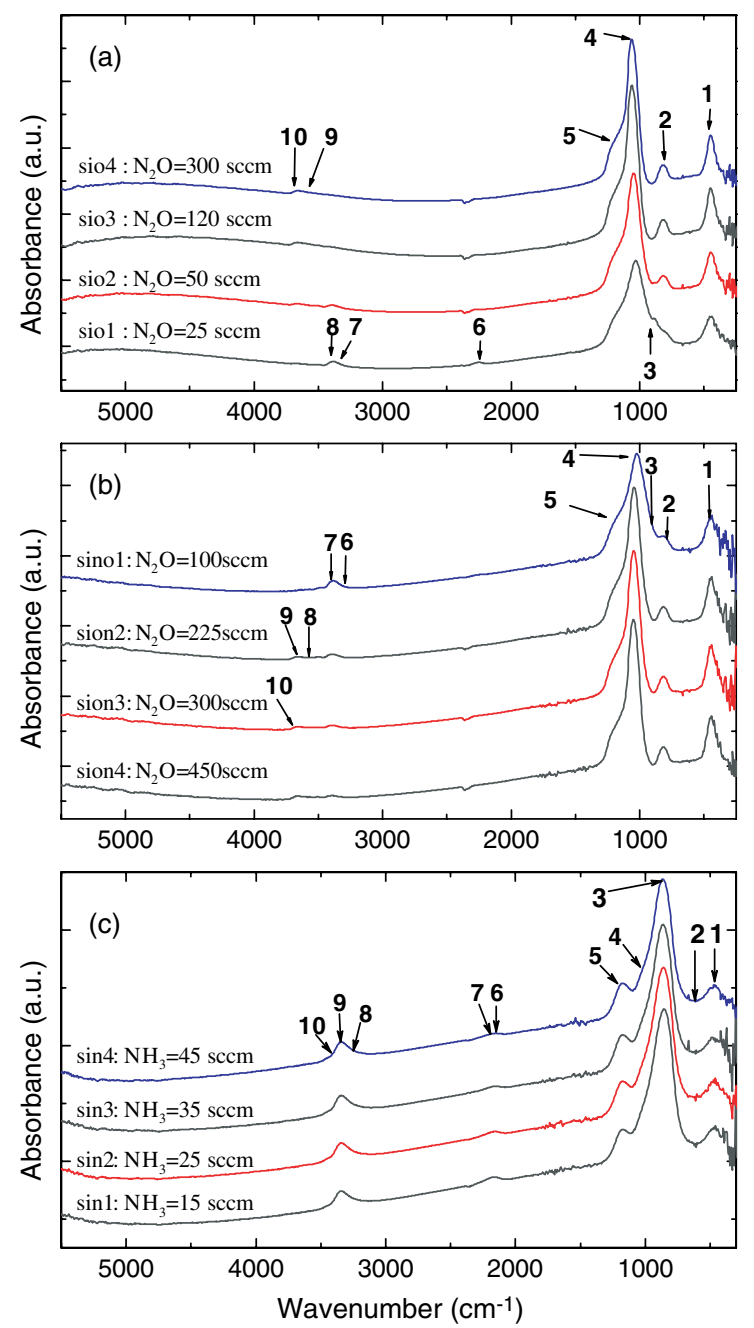

Fig. 3. Infrared absorption spectra as a function of $\mathrm{N}_{2} \mathrm{O}$ and $\mathrm{NH}_{3}$ flow rates for (a) silicon oxide, (b) silicon oxynitride and (c) silicon nitride films.

Table 2

Infrared vibrations observed in the silicon oxide samples

\begin{tabular}{|c|c|c|c|c|c|}
\hline \multirow[t]{2}{*}{ Vibration type } & \multicolumn{4}{|c|}{ Peak frequency $\left(\mathrm{cm}^{-1}\right)$} & \multirow[t]{2}{*}{ Ref. } \\
\hline & sio 1 & $\operatorname{sio} 2$ & sio3 & sio4 & \\
\hline (1) $\mathrm{Si}-\mathrm{O}$ rocking & 449 & 448 & 446 & 446 & {$[16,17]$} \\
\hline (2) $\mathrm{Si}-\mathrm{O}$ bending & 783 & 826 & 818 & 819 & {$[16,17]$} \\
\hline (3) $\mathrm{Si}-\mathrm{H}$ bending & 884 & - & - & - & {$[15,17]$} \\
\hline $\begin{array}{l}\text { (4) } \mathrm{Si}-\mathrm{O} \text { symmetric } \\
\text { stretching }\end{array}$ & 1026 & 1044 & 1053 & 1055 & {$[16,17]$} \\
\hline $\begin{array}{l}\text { (5) } \mathrm{Si}-\mathrm{O} \text { asymmetric } \\
\text { stretching }\end{array}$ & 1163 & 1179 & 1177 & 1179 & {$[15,16]$} \\
\hline (6) $\mathrm{Si}-\mathrm{H}$ stretching & 2258 & 2265 & - & - & {$[15,22,24]$} \\
\hline $\begin{array}{l}\text { (7) } \mathrm{N}-\mathrm{H} \cdots \mathrm{N} \\
\text { stretching }\end{array}$ & 3347 & 3360 & 3352 & 3398 & [21] \\
\hline (8) $\mathrm{N}-\mathrm{H}$ stretching & 3390 & 3399 & 3400 & 3398 & {$[21,24]$} \\
\hline $\begin{array}{l}\text { (9) } \mathrm{H}-\mathrm{O}-\mathrm{H} \\
\text { stretching }\end{array}$ & 3493 & 3499 & 3528 & 3542 & {$[22,24]$} \\
\hline (10) $\mathrm{SiO}-\mathrm{H}$ & 3657 & 3663 & 3671 & 3672 & {$[22,24]$} \\
\hline stretching & 3586 & 3595 & 3623 & 3628 & {$[22,24]$} \\
\hline
\end{tabular}

vibration was observed at lower frequencies compared to other samples. We attribute these features to the coupled vibration of the local structure of $\mathrm{Si}-\mathrm{O}-\mathrm{Si}-\mathrm{H}$, which was also observed by Wolfe et al. in siliconoxygen-carbon alloy thin films [17]. Relatively high refractive indices of the samples siol and sio2 suggest that they are relatively silicon rich. As the oxygen concentration in the film increases for sio 3 and sio4, the hydrogen present in the structure tends to form bonds with oxygen, instead of silicon or nitrogen. $\mathrm{N}-\mathrm{H}$ bond concentration which dominates $\mathrm{Si}-\mathrm{H}$ bonds in sample siol decreases to the limit of detection and is overtaken by $\mathrm{O}-\mathrm{H}$ bonds in sio4, which was grown at a higher $\mathrm{N}_{2} \mathrm{O}$ flow rate. Fig. 4 shows this in closer view. The absorption band of $\mathrm{N}-\mathrm{H}$ bond stretching is of special interest for optical applications, since it is the main cause of the optical absorption at $1.55 \mu \mathrm{m}$ wavelength in optical waveguides $[9,10]$. Therefore, special attention is paid to its properties and its evolution for the silicon oxide samples. The $\mathrm{N}-\mathrm{H}$ bond concentration was calculated for the four grown layers by using the technique of Lanford and Rand [18], using the expression

$[\mathrm{N}-\mathrm{H}]=\frac{1}{2.303 \times \sigma_{\mathrm{N}-\mathrm{H}}} \times \int_{\text {band }} \alpha(\omega) \mathrm{d} \omega$,

where $\sigma_{\mathrm{N}-\mathrm{H}}$ is the absorption cross-section for the $\mathrm{N}-\mathrm{H}$ bonds, $\int \alpha(\omega) \mathrm{d} \omega$ is the normalized absorption area of the band, and $\alpha=\frac{2.303}{t} \mathrm{~A}$ is the absorption coefficient, $A$ being the absorbance and $t$ the film thickness. The integration is carried over the band of consideration, which was decomposed using nonlinear curve fitting and assuming that the peaks are in the form of symmetric Gaussians. The results of this analysis are given in Table 3.

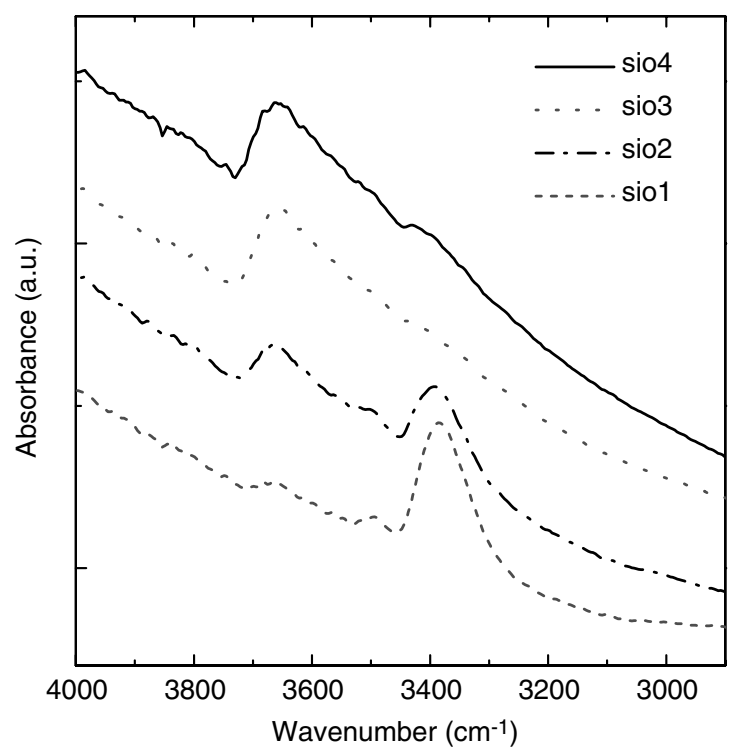

Fig. 4. Variation of the $\mathrm{O}-\mathrm{H}$ and $\mathrm{N}-\mathrm{H}$ stretching bands with the $\mathrm{N}_{2} \mathrm{O}$ flow rate for silicon oxide samples. 
Table 3

$\mathrm{N}-\mathrm{H}$ and $\mathrm{O}-\mathrm{H}$ bond concentration calculations for silicon oxide films by using FTIR transmittance spectroscopy

\begin{tabular}{|c|c|c|c|c|c|c|c|}
\hline Sample \# & $\begin{array}{l}\text { Refractive } \\
\text { index }\end{array}$ & Vibration type & $\omega\left(\mathrm{cm}^{-1}\right)$ & FWHM $\left(\mathrm{cm}^{-1}\right)$ & $\begin{array}{l}\text { Sum of the band } \\
\text { area }\left(10^{5} \mathrm{~cm}^{-2}\right)\end{array}$ & $\begin{array}{l}{[\mathrm{N}-\mathrm{H}]} \\
\left(10^{21} \mathrm{~cm}^{-3}\right)\end{array}$ & $\begin{array}{l}{[\mathrm{O}-\mathrm{H}]} \\
\left(10^{21} \mathrm{~cm}^{-3}\right)\end{array}$ \\
\hline \multirow[t]{5}{*}{ siol } & 1.53 & $\mathrm{~N}-\mathrm{H} \cdots \mathrm{N}$ & 3364 & 111 & & & \\
\hline & & $\mathrm{N}-\mathrm{H}$ & 3400 & 74 & 0.90 & 7.4 & - \\
\hline & & $\mathrm{H}-\mathrm{O}-\mathrm{H}$ & 3494 & 44 & & & \\
\hline & & $\mathrm{SiO}-\mathrm{H}(1)$ & 3586 & 114 & & & \\
\hline & & $\mathrm{SiO}-\mathrm{H}(2)$ & 3657 & 56 & 0.16 & - & 3.3 \\
\hline \multirow[t]{5}{*}{ sio2 } & 1.49 & $\mathrm{~N}-\mathrm{H} \cdots \mathrm{N}$ & 3360 & 106 & & & \\
\hline & & $\mathrm{N}-\mathrm{H}$ & 3399 & 71 & 0.50 & 4.1 & - \\
\hline & & $\mathrm{H}-\mathrm{O}-\mathrm{H}$ & 3499 & 60 & & & \\
\hline & & $\mathrm{SiO}-\mathrm{H}(1)$ & 3595 & 115 & & & \\
\hline & & $\mathrm{SiO}-\mathrm{H}(2)$ & 3664 & 64 & 0.45 & - & 9.2 \\
\hline \multirow[t]{5}{*}{$\operatorname{sio} 3$} & 1.47 & $\mathrm{~N}-\mathrm{H} \cdots \mathrm{N}$ & 3352 & 180 & & & \\
\hline & & $\mathrm{N}-\mathrm{H}$ & 3400 & 82 & 0.34 & 2.8 & - \\
\hline & & $\mathrm{H}-\mathrm{O}-\mathrm{H}$ & 3528 & 141 & & & \\
\hline & & $\mathrm{SiO}-\mathrm{H}(1)$ & 3623 & 88 & & & \\
\hline & & $\mathrm{SiO}-\mathrm{H}(2)$ & 3627 & 56 & 0.83 & - & 17.0 \\
\hline \multirow[t]{4}{*}{ sio4 } & 1.46 & $\mathrm{~N}-\mathrm{H} \cdots \mathrm{N}$ & 3398 & 90 & 0.06 & 0.4 & \\
\hline & & $\mathrm{H}-\mathrm{O}-\mathrm{H}$ & 3542 & 141 & & & \\
\hline & & $\mathrm{SiO}-\mathrm{H}(1)$ & 3628 & 83 & & & \\
\hline & & $\mathrm{SiO}-\mathrm{H}(2)$ & 3672 & 53 & 0.70 & - & 14.3 \\
\hline
\end{tabular}

The absorption cross-section value $\sigma_{\mathrm{N}-\mathrm{H}}=$ $5.3 \times 10^{-18} \mathrm{~cm}^{2}$ used in our calculations was obtained by Lanford and Rand [18] through a resonant nuclear reaction and the uncertainty of the calibration technique that they had proposed is reported to be about $\pm 15 \%$ [19]. The corresponding calibration factor for $\mathrm{O}-\mathrm{H}$ bonds however, is not so well defined. This factor was obtained by Rostaing et al. [20] through a fit to the data of elastic recoil detection analysis, precision of which is $\sim \pm 50 \%$. In spite of this, we believe that the results obtained can be used safely in comparison of the four samples, since the change in the $\mathrm{O}-\mathrm{H}$ concentration in these layers is more than $50 \%$. Nevertheless, care must be given when comparing concentrations of $\mathrm{N}-\mathrm{H}$ and $\mathrm{O}-\mathrm{H}$ bonds if absolute values are to be considered. For other quantities such as peak wavenumber $(\omega)$, full width at half maximum (FWHM), and normalized absorption band area $\left(\int \alpha \mathrm{d} \omega\right)$, of each absorption band we estimate typical uncertainty values of $\pm 5 \mathrm{~cm}^{-1}, \pm 5$ $\mathrm{cm}^{-1}$, and $\pm 4 \%$, respectively.

Looking closely at the results of Table 3 it is observed that the $\mathrm{N}-\mathrm{H}$ bond concentration of the samples decrease drastically from $0.74 \times 10^{22} \mathrm{~cm}^{-3}$ down to $0.04 \times 10^{22} \mathrm{~cm}^{-3}$ as the oxygen incorporation into the film is increased. The hydrogen atoms now tend to form bonds with oxygen, increasing the $\mathrm{O}-\mathrm{H}$ bond concentration from $0.42 \times 10^{22}$ to $1.83 \times 10^{22} \mathrm{~cm}^{-3}$ (Fig. 4). Moreover, the absorption due to $\mathrm{N}-\mathrm{H} \cdots \mathrm{N}$ vibrations arising from deformation of the local bond structure by forming hydrogen bonds, begins to dominate over the $\mathrm{N}-\mathrm{H}$ stretching vibration [21]. This is understood by recognizing the fact that, the available $\mathrm{N}-\mathrm{H}$ bonds are surrounded by an increased number of $\mathrm{O}-\mathrm{H}$ bonds, which in turn cause $\mathrm{N}-\mathrm{H}$ structure to form hydrogen bonding in increased quantities.

Finally, the conclusion that we draw from the compositional study of $\mathrm{SiO}_{x}$ films is that, the growth of the silicon oxynitride layers using higher flow rates of $\mathrm{N}_{2} \mathrm{O}$ should result in lower $\mathrm{N}-\mathrm{H}$ bond concentrations.

\subsubsection{SiN films}

The silicon nitride samples, used for infrared characterization, were deposited with the process parameters given previously in Table 1 . Four samples, $\sin 1, \sin 2$, $\sin 3$, and $\sin 4$ were used to trace their compositional properties with $\mathrm{NH}_{3}$ flow rates of $15,25,35$, and 45 sccm, respectively. The samples' film thicknesses were approximately $3000 \AA$, and their index of refraction varied between 1.85 and 1.81. The absorbance spectra of the above samples are given in Fig. 3(c), where the characteristic vibrations are enumerated and identified as given in Table 4.

The spectra are composed mainly of three regions. The first one with strongest features is composed of $\mathrm{Si}-$ $\mathrm{N}$ breathing $\left(\sim 470 \mathrm{~cm}^{-1}\right), \mathrm{Si}-\mathrm{H}$ rocking $\left(\sim 670 \mathrm{~cm}^{-1}\right)$, $\mathrm{Si}-\mathrm{N}$ stretching 1 and $2\left(\sim 850\right.$ and $\left.980 \mathrm{~cm}^{-1}\right)$, and $\mathrm{N}-\mathrm{H}$ bending $\left(\sim 1180 \mathrm{~cm}^{-1}\right)$ vibrations $[25,26]$. An interesting trend in this band is the shift of the $\mathrm{Si}-\mathrm{N}$ stretching vibration frequencies to higher values with increasing $\mathrm{NH}_{3}$ flow rate. The second region observed is at $(\sim 2200$ $\mathrm{cm}^{-1}$ ) and is due to $\mathrm{Si}-\mathrm{H}$ stretching vibrations. This band is resolved into two different components $\mathrm{Si}-$ $\mathrm{H}\left(\mathrm{N}_{2} \mathrm{Si}\right)$ and $\mathrm{Si}-\mathrm{H}\left(\mathrm{N}_{3}\right)$, accounted for by the variation in the local structure surrounding the $\mathrm{Si}-\mathrm{H}$ bonds [27]. 
Table 4

Infrared vibrations observed in the PECVD grown silicon nitride samples

\begin{tabular}{|c|c|c|c|c|c|}
\hline \multirow[t]{2}{*}{ Vibration type } & \multicolumn{4}{|c|}{ Peak frequency $\left(\mathrm{cm}^{-1}\right)$} & \multirow[t]{2}{*}{ Ref. } \\
\hline & $\sin 1$ & $\sin 2$ & $\sin 3$ & $\sin 4$ & \\
\hline (1) $\mathrm{Si}-\mathrm{N}$ breathing & 474 & 468 & 472 & 478 & {$[25]$} \\
\hline (2) $\mathrm{Si}-\mathrm{H}$ rocking & 665 & 663 & 673 & 673 & {$[25,26]$} \\
\hline (3) $\mathrm{Si}-\mathrm{N}$ stretching 1 & 843 & 850 & 857 & 860 & {$[25,26]$} \\
\hline (4) $\mathrm{Si}-\mathrm{N}$ stretching 2 & 957 & 972 & 996 & 1002 & {$[25]$} \\
\hline (5) $\mathrm{N}-\mathrm{H}$ bending & 1185 & 1184 & 1181 & 1179 & {$[25]$} \\
\hline (6) $\mathrm{Si}-\mathrm{H}\left(\mathrm{N}_{2} \mathrm{Si}\right)$ stretching & 2169 & 2158 & 2157 & 2162 & {$[27]$} \\
\hline (7) $\mathrm{Si}-\mathrm{H}\left(\mathrm{N}_{3}\right)$ stretching & 2250 & 2224 & 2220 & 2235 & [27] \\
\hline (8) $\mathrm{N}-\mathrm{H} \cdots \mathrm{N}$ stretching & 3290 & 3293 & 3294 & 3297 & [21] \\
\hline (9) $\mathrm{N}-\mathrm{H}$ stretching & 3346 & 3345 & 3345 & 3343 & {$[21,24,27]$} \\
\hline (10) $\mathrm{N}-\mathrm{H}_{2}$ stretching & 3464 & 3462 & 3460 & 3458 & {$[27]$} \\
\hline
\end{tabular}

The final region is that of $\mathrm{N}-\mathrm{H}$ stretching band, resolved into three different components as seen from Table 4 $[21,24,27]$.

The quantification of the hydrogen related bond concentrations is performed as described in the previous section. The results of this analysis are given in Table 5 . The absorption cross-section values used for $\mathrm{N}-\mathrm{H}$ and $\mathrm{Si}-\mathrm{H}$ bonds are $\sigma_{\mathrm{N}-\mathrm{H}}=5.3 \times 10^{-18} \mathrm{~cm}^{2}$ and $\sigma_{\mathrm{Si}-\mathrm{H}}=$ $7.4 \times 10^{-18} \mathrm{~cm}^{2}$, as reported by Lanford and Rand [18].
Typical uncertainties of the involved parameters are same as in the previous section.

The results of the calculations indicate that the $\mathrm{N}-\mathrm{H}$ bond concentration is steadily increasing from $7.94 \times 10^{22} \mathrm{~cm}^{-3}$ up to $9.59 \times 10^{22} \mathrm{~cm}^{-3}$ with the corresponding increase in $\mathrm{NH}_{3}$ gas flow rate. To monitor all the hydrogen concentration change in the films, the $\mathrm{Si}-$ $\mathrm{H}$ bond should be taken under consideration as well. By using the respective valencies of $\mathrm{N}$ and $\mathrm{H}$, and assuming

Table 5

$\mathrm{N}-\mathrm{H}$ and $\mathrm{Si}-\mathrm{H}$ bond concentration calculations for silicon nitride films by using FTIR transmittance spectroscopy

\begin{tabular}{|c|c|c|c|c|c|c|c|}
\hline Sample \# & $\begin{array}{l}\text { Refractive } \\
\text { index }\end{array}$ & Vibration type & $\omega\left(\mathrm{cm}^{-1}\right)$ & $\begin{array}{l}\text { FWHM } \\
\left(\mathrm{cm}^{-1}\right)\end{array}$ & $\begin{array}{l}\text { Sum of the band } \\
\text { area }\left(10^{5} \mathrm{~cm}^{-2}\right)\end{array}$ & $\begin{array}{l}{[\mathrm{N}-\mathrm{H}]} \\
\left(10^{22} \mathrm{~cm}^{-3}\right)\end{array}$ & $\begin{array}{l}{[\mathrm{Si}-\mathrm{H}]} \\
\left(10^{22} \mathrm{~cm}^{-3}\right)\end{array}$ \\
\hline \multirow[t]{7}{*}{$\sin 1$} & 1.85 & $\mathrm{~N}-\mathrm{H}$ bend & 1186 & 139 & & & \\
\hline & & $\mathrm{N}-\mathrm{H} \cdots$ stretching & 3290 & 238 & & & \\
\hline & & $\mathrm{N}-\mathrm{H}$ stretching & 3346 & 99 & & & \\
\hline & & $\mathrm{N}-\mathrm{H}_{2}$ stretching & 3464 & 47 & 9.7 & 7.9 & - \\
\hline & & $\mathrm{Si}-\mathrm{H}$ rock & 665 & 106 & & & \\
\hline & & $\mathrm{Si}-\mathrm{H}\left(\mathrm{N}_{2} \mathrm{Si}\right)$ stretching & 2169 & 100 & & & \\
\hline & & $\mathrm{Si}-\mathrm{H}\left(\mathrm{N}_{3}\right)$ stretching & 2250 & 92 & 2.5 & - & 1.8 \\
\hline \multirow[t]{7}{*}{$\sin 2$} & 1.83 & $\mathrm{~N}-\mathrm{H}$ bend & 1184 & 131 & & & \\
\hline & & $\mathrm{N}-\mathrm{H} \cdots$ stretching & 3293 & 249 & & & \\
\hline & & $\mathrm{N}-\mathrm{H}$ stretching & 3345 & 99 & & & \\
\hline & & $\mathrm{N}-\mathrm{H}_{2}$ stretching & 3462 & 43 & 10.2 & 8.4 & - \\
\hline & & $\mathrm{Si}-\mathrm{H}$ rock & 663 & 155 & & & \\
\hline & & $\mathrm{Si}-\mathrm{H}\left(\mathrm{N}_{2} \mathrm{Si}\right)$ stretching & 2158 & 90 & & & \\
\hline & & $\mathrm{Si}-\mathrm{H}\left(\mathrm{N}_{3}\right)$ stretching & 2224 & 125 & 2.9 & - & 2.0 \\
\hline \multirow[t]{7}{*}{$\sin 3$} & 1.83 & $\mathrm{~N}-\mathrm{H}$ bend & 1181 & 135 & & & \\
\hline & & $\mathrm{N}-\mathrm{H} \cdots$ stretching & 3294 & 243 & & & \\
\hline & & $\mathrm{N}-\mathrm{H}$ stretching & 3345 & 99 & & & \\
\hline & & $\mathrm{N}-\mathrm{H}_{2}$ stretching & 3460 & 43 & 11.2 & 9.2 & - \\
\hline & & $\mathrm{Si}-\mathrm{H}$ rock & 673 & 105 & & & \\
\hline & & $\mathrm{Si}-\mathrm{H}\left(\mathrm{N}_{2} \mathrm{Si}\right)$ stretching & 2157 & 87 & & & \\
\hline & & $\mathrm{Si}-\mathrm{H}\left(\mathrm{N}_{3}\right)$ stretching & 2219 & 82 & 2.0 & - & 1.5 \\
\hline \multirow[t]{7}{*}{$\sin 4$} & 1.81 & $\mathrm{~N}-\mathrm{H}$ bend & 1179 & 137 & & & \\
\hline & & $\mathrm{N}-\mathrm{H} \cdots$ stretching & 3297 & 263 & & & \\
\hline & & $\mathrm{N}-\mathrm{H}$ stretching & 3343 & 99 & & & \\
\hline & & $\mathrm{N}-\mathrm{H}_{2}$ stretching & 3458 & 36 & 11.7 & 9.6 & - \\
\hline & & $\mathrm{Si}-\mathrm{H}$ rock & 673 & 130 & & & \\
\hline & & $\mathrm{Si}-\mathrm{H}\left(\mathrm{N}_{2} \mathrm{Si}\right)$ stretching & 2162 & 92 & & & \\
\hline & & $\mathrm{Si}-\mathrm{H}\left(\mathrm{N}_{3}\right)$ stretching & 2235 & 92 & 2.4 & - & 1.7 \\
\hline
\end{tabular}


Table 6

Variation of the $\mathrm{N}-\mathrm{H}$ bond, $\mathrm{Si}-\mathrm{H}$ bond and total hydrogen concentrations for the silicon nitride samples

\begin{tabular}{llll}
\hline Sample \# & $\begin{array}{l}{[\mathrm{N}-\mathrm{H}]} \\
\left(10^{22} \mathrm{~cm}^{-3}\right)\end{array}$ & $\begin{array}{l}{[\mathrm{Si}-\mathrm{H}]} \\
\left(10^{22} \mathrm{~cm}^{-3}\right)\end{array}$ & $\begin{array}{l}{[\mathrm{H}]} \\
\left(10^{22} \mathrm{~cm}^{-3}\right)\end{array}$ \\
\hline $\sin 1$ & 7.9 & 1.8 & 9.7 \\
$\sin 2$ & 8.4 & 2.0 & 10.4 \\
$\sin 3$ & 9.2 & 1.5 & 10.6 \\
$\sin 4$ & 9.6 & 1.7 & 11.3 \\
\hline
\end{tabular}

that there are no $\mathrm{N}-\mathrm{N}$ and $\mathrm{H}-\mathrm{H}$ bonds present in the layers, we relate the atomic concentration to the bond concentration in the following way:

$[\mathrm{H}]=[\mathrm{N}-\mathrm{H}]+[\mathrm{Si}-\mathrm{H}]$.

The results of these calculations for the silicon nitride samples are given in Table 6. As expected, the total hydrogen concentration in the samples has increased steadily with $\mathrm{NH}_{3}$ flow rate. In the band of interest $(\mathrm{N}-$ $\mathrm{H}$ stretching), large hydrogen concentration has important impacts. Namely, as the number of $\mathrm{N}-\mathrm{H}$ bonds in the layers increases, the contributions from $\mathrm{N}-$ $\mathrm{H} \cdots \mathrm{N}$ vibrational absorption increases as well. This bonding type, as proposed by Yin and Smith, takes place between the hydrogen atoms in the $\mathrm{N}-\mathrm{H}$ bonds and lone pair electrons of nearby $\mathrm{N}$ atoms [21]. In the samples investigated, the hydrogen bonding influences the characteristics of $\mathrm{N}-\mathrm{H}$ bond in a way that the original stretching vibration shifts to lower wavenumbers and becomes much broader. The frequency difference between the $\mathrm{N}-\mathrm{H}$ and $\mathrm{N}-\mathrm{H} \cdots \mathrm{N}$ stretching modes is about $\sim 50 \mathrm{~cm}^{-1}$ and difference in the FWHM is in the order of $\sim 100 \mathrm{~cm}^{-1}$. In addition, as the amount of hydrogen in the layers increases there is a slight shift of $\sim 7 \mathrm{~cm}^{-1}$ towards lower frequencies and an increase in the FWHM value of about $\sim 25 \mathrm{~cm}^{-1}$.

As a concluding remark, the compositional study of silicon nitride films has shown that an increase in the flow rate of $\mathrm{NH}_{3}$ results in large increases in the concentrations of hydrogen. For the growth of low optical loss silicon oxynitride layers, care should be given to the complications that may arise from the high flow rate of this gaseous precursor.

\subsection{3. $\mathrm{SiO}_{x} N_{y}$ films}

Silicon oxynitride samples, used in FTIR transmittance characterizations were deposited at $350{ }^{\circ} \mathrm{C}$, an RF power of $10 \mathrm{~W}$, constant $2 \% \mathrm{SiH}_{4} / \mathrm{N}_{2}$ flow rate of 180 sccm, and process pressure of 1 Torr (see Table 1). The samples were obtained with $\mathrm{NH}_{3}$ flow rate of $15 \mathrm{sccm}$ and $\mathrm{N}_{2} \mathrm{O}$ flow rates of $100,225,300$, and $450 \mathrm{sccm}$ and were named as sion1, sion2, sion3, and sion4, respectively. The grown film thicknesses were about $\sim 4500 \AA$ and had index of refraction values between 1.54 and 1.48 .
Table 7

Infrared vibrations observed in the silicon oxynitride samples

\begin{tabular}{lrrrc}
\hline Vibration type & \multicolumn{4}{c}{ Peak frequency $\left(\mathrm{cm}^{-1}\right)$} \\
\cline { 2 - 5 } & sion1 & sion2 & sion3 & sion4 \\
\hline (1) Si-O rocking & 449 & 445 & 446 & 443 \\
(2) Si-O bending & 815 & 817 & 816 & 817 \\
(3) Si-N stretching & 923 & 983 & - & - \\
(4) Si-O symmetric & 1018 & 1042 & 1040 & 1044 \\
$\quad$ stretching & & & & \\
(5) Si-O asymmetric & 1154 & 1144 & 1130 & 1167 \\
stretching & & & & \\
(6) N-H - N stretching & 3341 & 3345 & 3351 & 3358 \\
(7) N-H stretching & 3389 & 3396 & 3399 & 3403 \\
(8) H-O-H stretching & 3493 & 3499 & 3499 & 3499 \\
(9) SiO-H stretching & 3571 & 3578 & 3589 & 3589 \\
(10) SiO-H stretching & 3651 & 3666 & 3668 & 3670 \\
\hline
\end{tabular}

The FTIR transmittance measurements were done in a similar manner as with silicon oxide and nitride films. The absorbance spectra of the samples are depicted in Fig. 3(b) with the characteristic absorption bands enumerated and identified as in Table 7 . In the infrared spectra, the dominant feature is that of $\mathrm{Si}-\mathrm{O}$ stretching vibration at $\sim 1040 \mathrm{~cm}^{-1}$, which resembles the features typically observed in silicon oxide films $[16,17]$. The $\mathrm{Si}-$ $\mathrm{O}$ rocking and bending vibrations are detected at $\sim 445$ and $\sim 815 \mathrm{~cm}^{-1}$, respectively, which is exactly at the same position as in the silicon oxide samples [20]. Moreover, the $\mathrm{Si}-\mathrm{N}$ stretching vibration was observable only for the samples sion1 and sion2. For all the other samples it was not possible to decompose the band in a way to include this vibration. Most probably, as the $\mathrm{N}_{2} \mathrm{O}$ flow rate is increased, the bonding of silicon with oxygen is enhanced and the remaining $\mathrm{Si}-\mathrm{N}$ bonds are just obscured by it.

As for the $\mathrm{N}-\mathrm{H}$ absorption band, its evolution for the four samples together with the decomposed components is given in Fig. 5. It is clearly seen that for the samples with higher oxygen flow rate, the $\mathrm{N}-\mathrm{H}$ bond absorption has decreased, while the number of $\mathrm{O}-\mathrm{H}$ bonds has increased. The cross-section values for the $\mathrm{N}-\mathrm{H}$ and $\mathrm{O}-\mathrm{H}$ bonds is identical with the one used for silicon oxide films. Typical uncertainty values of the involved parameters are as in Section 3.2.1. The results of the quantitative calculations are given in Table 8 .

First bond concentrations for silicon oxynitride films and their counterparts in silicon oxide and nitride layers are compared. Beginning with the critical bonding type, $\mathrm{N}-\mathrm{H}$, in silicon oxide samples, its concentration varied between $(0.74$ and 0.04$) \times 10^{22} \mathrm{~cm}^{-3}$, with corresponding $\mathrm{N}_{2} \mathrm{O}$ flow rate ranging between 25 and $300 \mathrm{sccm}$. In silicon nitride samples, the $\mathrm{N}-\mathrm{H}$ bond concentration was found to vary in the range $(7.9-11.7) \times 10^{22} \mathrm{~cm}^{-3}$, more than a factor of 9 greater than in silicon oxide layers, with corresponding $\mathrm{NH}_{3}$ flow rates of 15-45 sccm. As for the silicon oxynitride layers, which were 

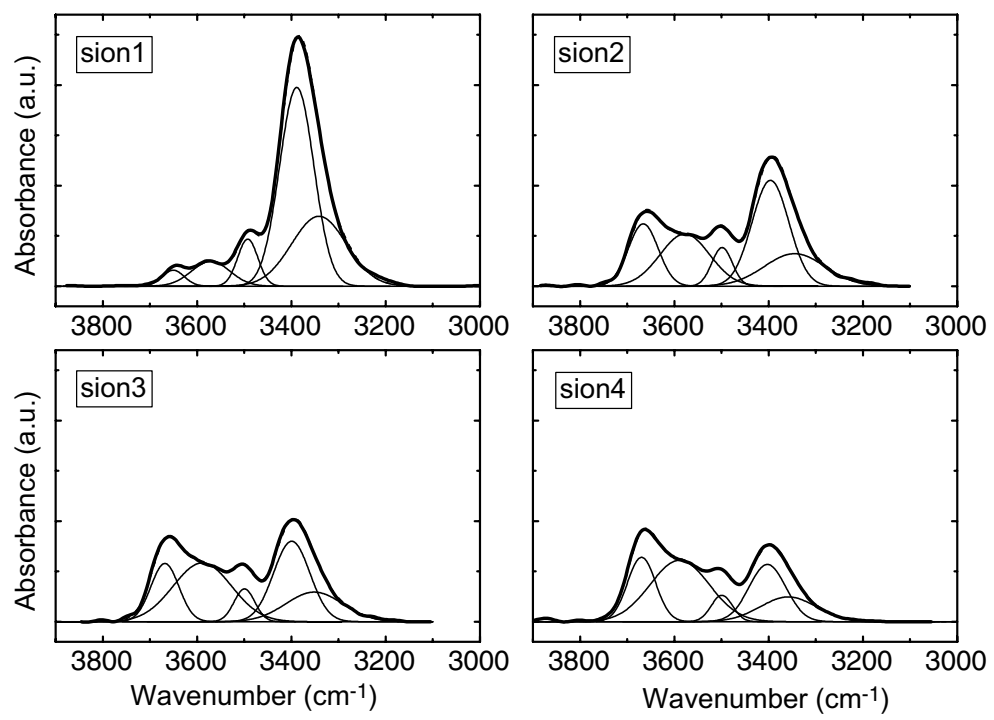

Fig. 5. Gaussian deconvolution of the $\mathrm{O}-\mathrm{H}$ and $\mathrm{N}-\mathrm{H}$ absorption bands for the samples sion1-sion4.

Table 8

$\mathrm{N}-\mathrm{H}$ and $\mathrm{O}-\mathrm{H}$ bond concentration calculations for silicon oxynitride films by using FTIR transmittance spectroscopy

\begin{tabular}{|c|c|c|c|c|c|c|c|}
\hline Sample \# & $\begin{array}{l}\text { Refractive } \\
\text { index }\end{array}$ & Vibration type & $\omega\left(\mathrm{cm}^{-1}\right)$ & FWHM $\left(\mathrm{cm}^{-1}\right)$ & $\begin{array}{l}\text { Sum of the band } \\
\text { area }\left(10^{5} \mathrm{~cm}^{-2}\right)\end{array}$ & $\begin{array}{l}{[\mathrm{N}-\mathrm{H}]} \\
\left(10^{22} \mathrm{~cm}^{-3}\right)\end{array}$ & $\begin{array}{l}{[\mathrm{O}-\mathrm{H}]} \\
\left(10^{22} \mathrm{~cm}^{-3}\right)\end{array}$ \\
\hline \multirow[t]{5}{*}{ sion1 } & 1.54 & $\mathrm{~N}-\mathrm{H} \cdots \mathrm{N}$ stretching & 3341 & 137 & & & \\
\hline & & $\mathrm{N}-\mathrm{H}$ stretching & 3389 & 86 & 1.47 & 1.2 & - \\
\hline & & $\mathrm{H}-\mathrm{O}-\mathrm{H}$ & 3493 & 50 & & & \\
\hline & & $\mathrm{SiO}-\mathrm{H}(1)$ & 3571 & 95 & & & \\
\hline & & $\mathrm{SiO}-\mathrm{H}(2)$ & 3651 & 55 & 0.31 & - & 0.6 \\
\hline \multirow[t]{5}{*}{$\operatorname{sion} 2$} & 1.49 & $\mathrm{~N}-\mathrm{H} \cdots \mathrm{N}$ stretching & 3345 & 152 & & & \\
\hline & & $\mathrm{N}-\mathrm{H}$ stretching & 3396 & 92 & 0.75 & 0.6 & - \\
\hline & & $\mathrm{H}-\mathrm{O}-\mathrm{H}$ & 3499 & 51 & & & \\
\hline & & $\mathrm{SiO}-\mathrm{H}(1)$ & 3578 & 124 & & & \\
\hline & & $\mathrm{SiO}-\mathrm{H}(2)$ & 3666 & 74 & 0.67 & - & 1.5 \\
\hline \multirow[t]{5}{*}{ sion 3} & 1.50 & $\mathrm{~N}-\mathrm{H} \cdots \mathrm{N}$ stretching & 3351 & 142 & & & \\
\hline & & $\mathrm{N}-\mathrm{H}$ stretching & 3399 & 91 & 0.60 & 0.5 & - \\
\hline & & $\mathrm{H}-\mathrm{O}-\mathrm{H}$ & 3499 & 52 & & & \\
\hline & & $\mathrm{SiO}-\mathrm{H}(1)$ & 3589 & 146 & & & \\
\hline & & $\mathrm{SiO}-\mathrm{H}(2)$ & 3668 & 70 & 0.74 & - & 1.5 \\
\hline \multirow[t]{5}{*}{ sion4 } & 1.48 & $\mathrm{~N}-\mathrm{H} \cdots \mathrm{N}$ stretching & 3358 & 139 & & & \\
\hline & & $\mathrm{N}-\mathrm{H}$ stretching & 3403 & 91 & 0.45 & 0.4 & - \\
\hline & & $\mathrm{H}-\mathrm{O}-\mathrm{H}$ & 3499 & 53 & & & \\
\hline & & $\mathrm{SiO}-\mathrm{H}(1)$ & 3589 & 147 & & & \\
\hline & & $\mathrm{SiO}-\mathrm{H}(2)$ & 3670 & 70 & 0.81 & - & 1.7 \\
\hline
\end{tabular}

grown with constant $\mathrm{NH}_{3}$ flow of $15 \mathrm{sccm}$ and varying flow of $\mathrm{N}_{2} \mathrm{O}$ between 100 and $450 \mathrm{sccm}$, the $\mathrm{N}-\mathrm{H}$ bond concentration ranged between $1.2 \times 10^{22}$ and $3.7 \times 10^{21}$ $\mathrm{cm}^{-3}$. The comparison of the $\mathrm{N}-\mathrm{H}$ bond concentration variation with $\mathrm{N}_{2} \mathrm{O}$ flow rate for silicon oxynitride and oxide samples is illustrated in Fig. 6. We observe that for both type of the films there is a decrease in the $\mathrm{N}-\mathrm{H}$ bond concentration by a factor of three with increasing $\mathrm{N}_{2} \mathrm{O}$ flow rate.

From Table 8 we see that for both types of films, there is a trend of increase in the number of $\mathrm{O}-\mathrm{H}$ bonds as $\mathrm{N}_{2} \mathrm{O}$ flow rate is increased. In addition, if we specifically monitor the $\mathrm{N}-\mathrm{H} \cdots \mathrm{N}$ bonding related absorption, we observe a decrease in concentration, as well. This is due to the fact that hydrogen now forms bonds mainly with oxygen, resulting in less $\mathrm{N}-\mathrm{H}$ and thus $\mathrm{N}-\mathrm{H} \cdots \mathrm{N}$ bonds, being consistent with our results [21]. As for the other bond types, it was observed that the number of the $\mathrm{Si}-\mathrm{O}$ bonds increases steadily with increasing $\mathrm{N}_{2} \mathrm{O}$ flow, which is expected. Here, it should be noted that the $\mathrm{Si}-\mathrm{O}$ bonds seem to dominate over $\mathrm{Si}-\mathrm{N}$ bonds, consistent with the previous explanation for $\mathrm{N}-\mathrm{H}$ bonds. 


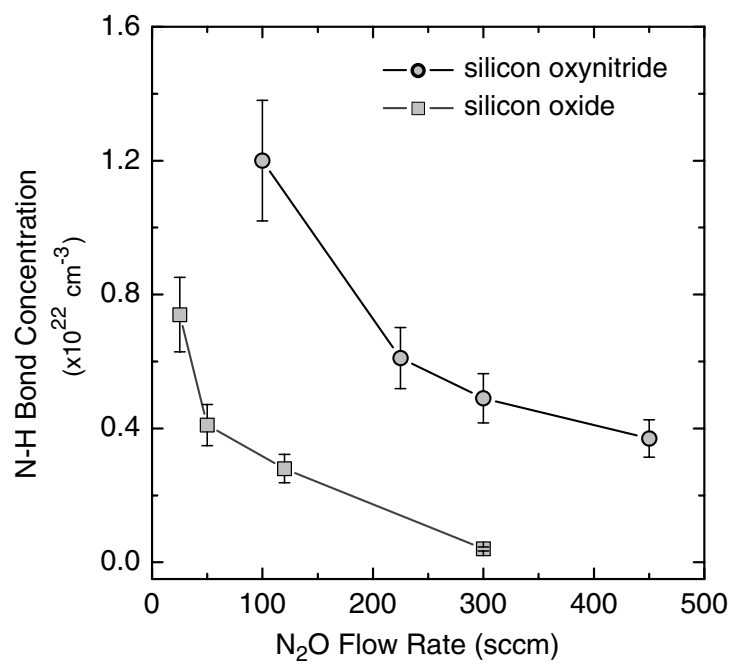

Fig. 6. $\mathrm{N}-\mathrm{H}$ bond concentration variation with $\mathrm{N}_{2} \mathrm{O}$ flow rate for silicon oxynitride and silicon oxide films.

The variation of the total hydrogen concentration for silicon oxynitride films were calculated by using the relation [20]

$[\mathrm{H}]=[\mathrm{N}-\mathrm{H}]+[\mathrm{O}-\mathrm{H}]$.

As a result, for the samples sion1-sion4 the corresponding hydrogen concentrations were found to be $(1.8,2.1,2.0$, and 2.0$) \times 10^{22} \mathrm{~cm}^{-3}$, respectively. Comparing the hydrogen content of the two samples (sion3 and sio3), latter having a value of $1.5 \times 10^{22} \mathrm{~cm}^{-3}$, shows that the hydrogen concentration of the silicon oxynitride sample is about $54 \%$ larger. On the other hand, sample $\sin 1$, which was grown with $\mathrm{NH}_{3}$ flow of $15 \mathrm{sccm}$ as was done in samples sion1-sion4. Its hydrogen concentration is $9.7 \times 10^{22} \mathrm{~cm}^{-3}$ being 6.6 times more than that of sample sio 3 and 4.5 times more than the sample sion 3 .

The infrared study on silicon oxide, nitride, and oxynitride films has proven to be an effective method for compositional analysis of the grown layers. As was aimed, the growth conditions affecting the hydrogen incorporation into the films were identified. In particular, the silicon oxynitride films were shown to have more resemblance with the oxide layers than nitride films, in terms of both the types of detected vibrations and their amount in the films.

\subsection{Annealing study}

In the hopes of using as the core of optical waveguide, a specific SiON layer was chosen for an annealing study. In choosing the specific oxynitride film type two factors were considered. First, refractive index of the film was chosen to be 1.50. Second, the amount of $\mathrm{N}-\mathrm{H}$ bond present in the silicon oxynitride layer should be minimum. Therefore, a silicon oxynitride film of refractive index of $\sim 1.50$, corresponding to flow rates of $\mathrm{NH}_{3}$ and
$\mathrm{N}_{2} \mathrm{O}$ of $15 \mathrm{sccm}$ and $225 \mathrm{sccm}$, respectively (sample sion2) was selected.

This sample still contains small amount of $\mathrm{N}-\mathrm{H}$ bonds, which is known to be the main cause of optical absorption in the waveguides. Therefore, an annealing treatment was performed in order to decrease or eliminate this type of bonding from the film structure [23]. For this purpose, a commercial Protherm furnace, capable of annealing samples up to a maximum temperature of $1350{ }^{\circ} \mathrm{C}$ was employed. The samples to be annealed were placed on a quartz boat inside an alsint tube of $110 \mathrm{~cm}$ length and diameter of $5 \mathrm{~cm}$. Inside the tube a constant ambient of pure nitrogen was set up, the flow rate of which was held fixed at $7 \mathrm{l} / \mathrm{min}$. Water cooled caps were attached on both ends of the tube. During the experiments, the temperature in the neighborhood of the sample was monitored using a chromelalumel thermocouple (TC). A built-in temperature controller was employed in order to program annealing cycle.

In order to observe the changes in the $\mathrm{N}-\mathrm{H}$ bond concentration in the layers with temperature, four different annealing programs were run. The programs had equal ramping rates between $0-700{ }^{\circ} \mathrm{C}$ and $700-T_{\max }$ with $2 \mathrm{~h}$ of annealing at maximum temperature. Four programs at temperatures of $800,900,1000$, and 1100 ${ }^{\circ} \mathrm{C}$ were applied. The samples studied were deposited at identical conditions as mentioned in the previous section. Their FTIR transmittance measurements were performed similarly to as-deposited silicon oxide and oxynitride samples. The absorbance spectra of the layers are depicted in Fig. 7, and identification of the absorption bands is listed in Table 9.

The annealing treatment had striking effects on the infrared spectra. We observe a definite trend for

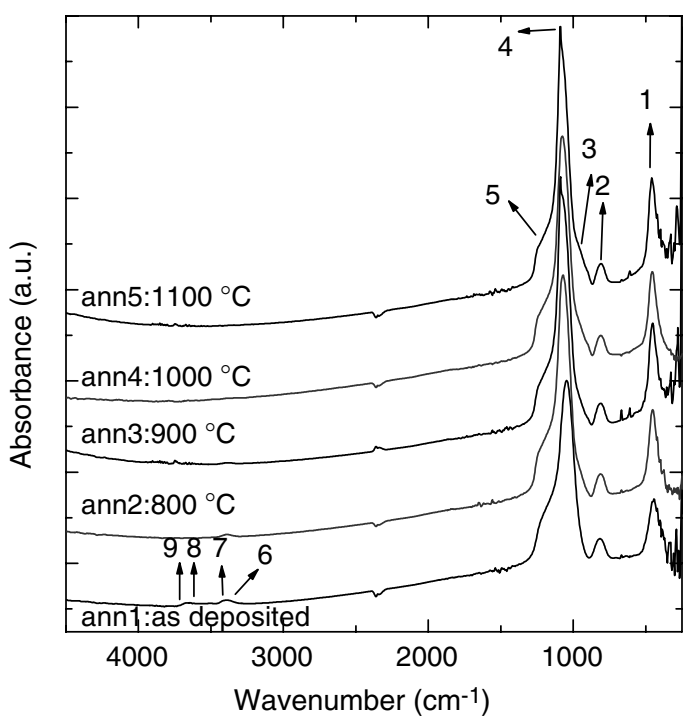

Fig. 7. IR absorbance spectra of silicon oxynitride films annealed at $800,900,1000$ and $1100{ }^{\circ} \mathrm{C}$. 
Table 9

Infrared vibrations observed in the annealed silicon oxynitride samples (the sample ann 1 is as-deposited SiON layer for comparison purposes)

\begin{tabular}{lrrrrr}
\hline Vibration type & \multicolumn{7}{c}{ Peak frequency $\left(\mathrm{cm}^{-1}\right)$} & & \\
\cline { 2 - 6 } & ann1 & ann2 & ann3 & ann4 & ann5 \\
\hline (1) $\mathrm{Si}-\mathrm{O}$ rocking & 442 & 452 & 451 & 453 & 454 \\
(2) $\mathrm{Si}-\mathrm{O}$ bending & 817 & 812 & 812 & 809 & 808 \\
(3) $\mathrm{Si}-\mathrm{N}$ stretching & 980 & 971 & 1024 & 988 & 1034 \\
(4) $\mathrm{Si}-\mathrm{O}$ symmetric & 1044 & 1065 & 1073 & 1071 & 1079 \\
stretching & & & & & \\
(5) $\mathrm{Si}-\mathrm{O}$ asymmetric & 1153 & 1182 & 1189 & 1185 & 1196 \\
stretching & & & & & \\
(6) N-H - N stretching & 3344 & - & - & - & - \\
(7) N-H stretching & 3399 & 3389 & 3386 & - & - \\
(8) H-O-H stretching & 3501 & - & - & - & - \\
(9) SiO-H stretching & 3582 & - & - & - & - \\
(10) SiO-H stretching & 3666 & - & - & - & \\
\hline
\end{tabular}

narrowing of the bands, which means that the extent of different atomic arrangements surrounding the bonds has decreased. This, in turn, implies that the structure of the layer has become more ordered. In addition, a strong shift of the $\mathrm{Si}-\mathrm{O}-\mathrm{Si}$ stretching frequency is evidenced. It is attributed to the shortening of the average bond lengths leading to an increase in the average vibrational frequency [23]. Moreover, the increase in the stretching frequency of the $\mathrm{Si}-\mathrm{O}-\mathrm{Si}$ stretching vibration up to $1079 \mathrm{~cm}^{-1}$ means that the $\mathrm{Si}-\mathrm{O}-\mathrm{Si}$ angle increases to the value corresponding to that of thermally grown silicon oxide layers.

This process was accompanied by densification of the films, which lead to a clearly observed tensile stress in our structures. The as-deposited film thicknesses of the samples were about $4700 \AA$. As is observed from Fig. 8, for annealing temperatures of $800-1200{ }^{\circ} \mathrm{C}$, the film thicknesses decreased in the range of $0-7 \%$.

The most important feature of the spectra is the strong reduction of the vibrations related to hydrogen. In order to relate its concentration in the films to the annealing temperature, an analysis similar to those done for oxide, nitride, and oxynitride layers previously was performed. The results are tabulated in Table 10.

The evolution of the $\mathrm{N}-\mathrm{H}$ stretching band with the annealing temperature is given in Fig. 9 in detail. It is obvious that the $\mathrm{O}-\mathrm{H}$ related absorption bands are eliminated upon annealing at $800{ }^{\circ} \mathrm{C}$, while the $\mathrm{N}-\mathrm{H}$ stretching vibration is still detectable. Nevertheless, with

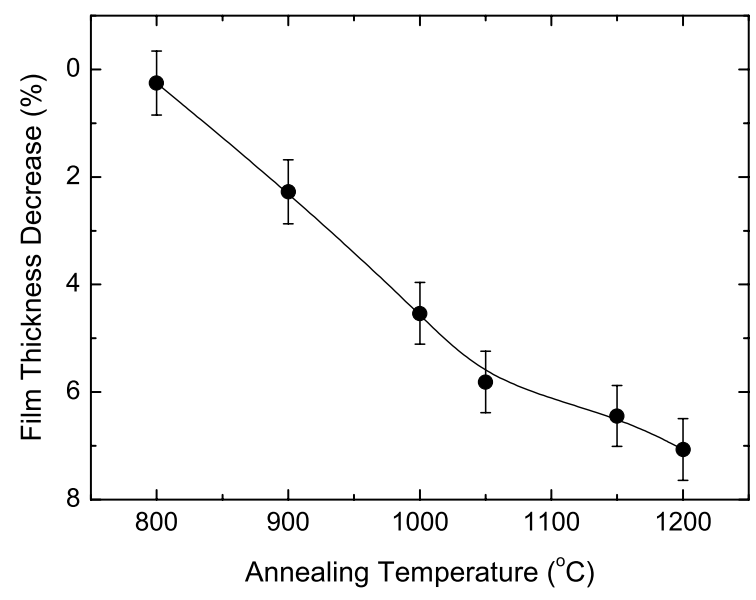

Fig. 8. Variation of the film thickness decrease for silicon oxynitride films at various annealing temperatures.

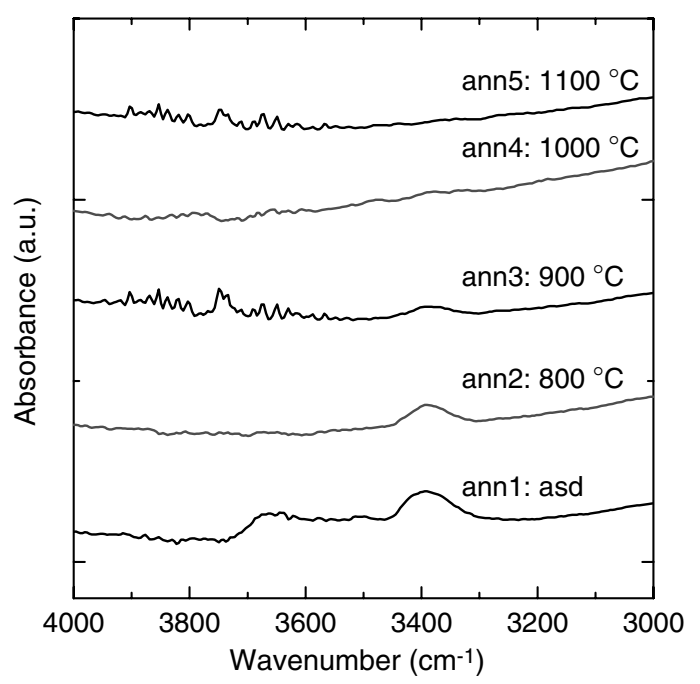

Fig. 9. Evolution of the $\mathrm{N}-\mathrm{H}$ stretching band with the annealing temperature.

increasing annealing temperature, the area of this band also decreases and vanishes below the detection limit at temperature of $1000{ }^{\circ} \mathrm{C}$. The quantitative variation of the $\mathrm{N}-\mathrm{H}$ bond concentration with the annealing temperature is given in Fig. 10. The total hydrogen concentration in the as-deposited films is expected to be slightly more than the value given in Table 10 , because the $\mathrm{N}-\mathrm{H}$ bending vibration is obscured due to $\mathrm{Si}-\mathrm{O}$

Table 10

$\mathrm{N}-\mathrm{H}$ bond concentration calculations for the annealed silicon oxynitride films by using FTIR transmittance spectroscopy

\begin{tabular}{|c|c|c|c|c|c|c|c|}
\hline Sample \# & $\begin{array}{l}\text { Annealing } \\
\text { temperature }{ }^{\circ} \mathrm{C}\end{array}$ & $\begin{array}{l}\text { Refractive } \\
\text { index }\end{array}$ & Vibration type & $\omega\left(\mathrm{cm}^{-1}\right)$ & FWHM $\left(\mathrm{cm}^{-1}\right)$ & $\begin{array}{l}\text { Sum of the band } \\
\text { area }\left(10^{4} \mathrm{~cm}^{-2}\right)\end{array}$ & $\begin{array}{l}\mathrm{N}-\mathrm{H}] \\
\left(10^{21} \mathrm{~cm}^{-3}\right)\end{array}$ \\
\hline ann2 & 800 & 1.48 & N-H stretching & 3389 & 81 & 2.5 & 2.0 \\
\hline ann3 & 900 & 1.48 & $\mathrm{~N}-\mathrm{H}$ stretching & 3386 & 77 & 1.1 & 0.9 \\
\hline ann3 & 1000 & 1.49 & $\mathrm{~N}-\mathrm{H}$ stretching & - & - & - & - \\
\hline ann3 & 1100 & 1.49 & $\mathrm{~N}-\mathrm{H}$ stretching & - & - & - & - \\
\hline
\end{tabular}




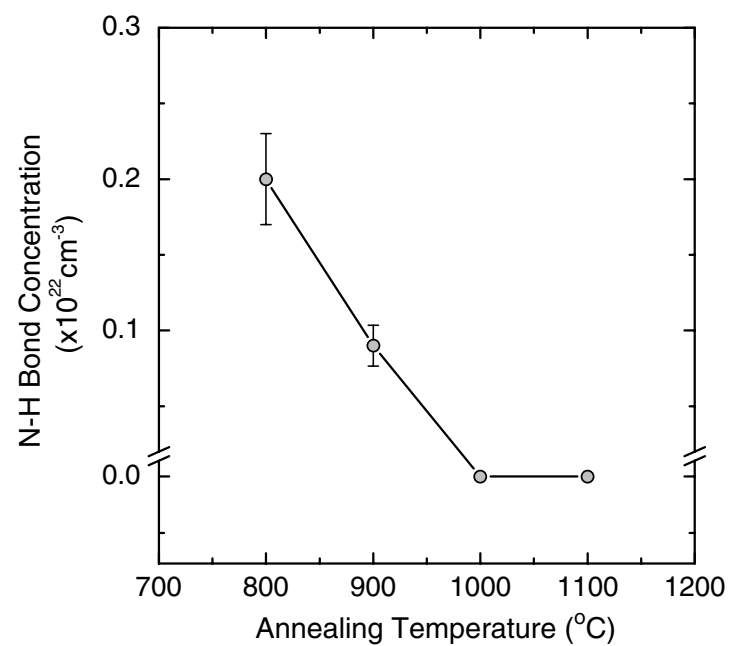

Fig. 10. Evolution of the $\mathrm{N}-\mathrm{H}$ bond stretching concentration with the annealing temperature.

stretching absorption at $\sim 1150 \mathrm{~cm}^{-1}$. However, if we analyze the $\mathrm{Si}-\mathrm{O}$ stretching bands of the sample ann5 (annealed at $1100{ }^{\circ} \mathrm{C}$ ), in which we expect no observable $\mathrm{N}-\mathrm{H}$ bonds, we see that there is no considerable difference, indicating that the contribution of $\mathrm{N}-\mathrm{H}$ bending to be very small. We also observe that $\mathrm{N}-\mathrm{H}$ bond stretching concentration decreases from $0.52 \times 10^{22} \mathrm{~cm}^{-3}$ for the as-deposited sample (ann1), to $0.09 \times 10^{22} \mathrm{~cm}^{-3}$ for the sample ann 3 annealed at $900{ }^{\circ} \mathrm{C}$ and goes below our detection limit after $1000{ }^{\circ} \mathrm{C}$. Thus, according to this analysis, the aim of eliminating the $\mathrm{N}-\mathrm{H}$ bonds is achieved at an annealing temperature of $1000{ }^{\circ} \mathrm{C}$.

\subsection{ATR technique}

To push our detection limit further, we have employed the more sensitive technique of attenuated total reflection (ATR). For this purpose, we have used a silicon ATR crystal of $45^{\circ}$ with dimensions $5 \mathrm{~mm} \times 3$ $\mathrm{mm} \times 50 \mathrm{~mm}$ (see inset of Fig. 11). The films to be analyzed were grown on the crystal, after which they were annealed and ATR spectra taken by using a special attachment. The advantage of this technique comes from the multiple internal reflections that take place in the crystal. As the refractive index of the deposited films is much smaller than that of the ATR crystal, only evanescent waves penetrate into the grown film. For our case, the total number of internal reflections is calculated to be about 16, resulting in enhanced absorption spectra.

The films used in ATR characterizations were about $\sim 0.5 \mu \mathrm{m}$ thick. With identical conditions of the FTIR setup with the previous measurements and perpendicular incidence of the light onto inclined side of the crystal, four spectra were taken. The analyzed samples were annealed at 900 and $1000{ }^{\circ} \mathrm{C}$ identically as the samples

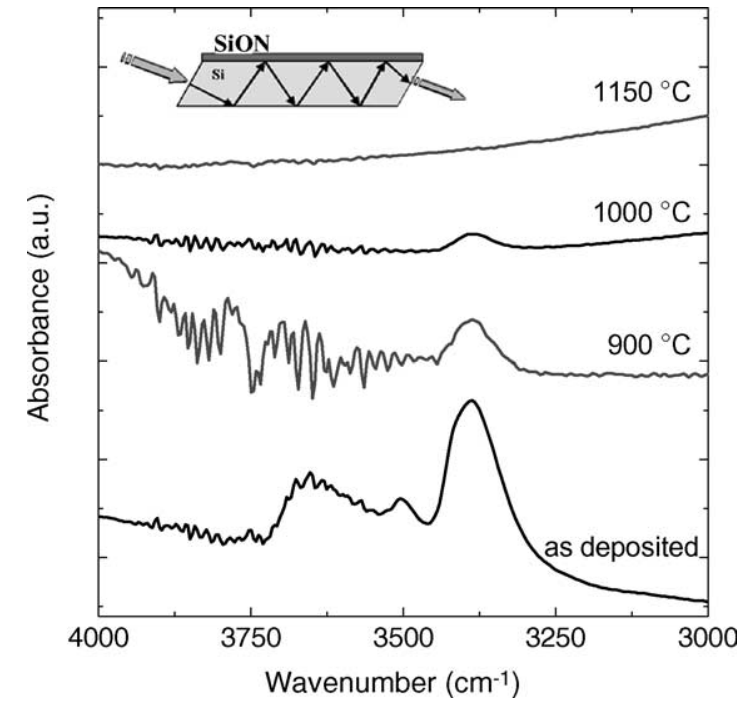

Fig. 11. $\mathrm{O}-\mathrm{H}$ and $\mathrm{N}-\mathrm{H}$ stretching band variation with annealing temperature as detected by ATR infrared spectroscopy.

ann 3 and ann4. In addition, one more annealing regime was performed at temperature of $1150{ }^{\circ} \mathrm{C}$ but now for 4 $\mathrm{h}$. The spectra for the $\mathrm{N}-\mathrm{H}$ stretching vibration region is given in Fig. 11. From the ATR analysis the presence of the $\mathrm{N}-\mathrm{H}$ stretching vibration related absorption at 1000 ${ }^{\circ} \mathrm{C}$ annealing is strongly evident, in contrast with the spectra of Fig. 9, in which it was below the detection limit. Moreover, for an annealing program of $4 \mathrm{~h}$ at $1150{ }^{\circ} \mathrm{C}$, the $\mathrm{N}-\mathrm{H}$ bond concentration in the film may be assumed to be negligible.

In conclusion, we have verified by infrared transmission and ATR analysis that there is no observable $\mathrm{N}-\mathrm{H}$ bond present in the structure of the films, after an annealing program at $1150{ }^{\circ} \mathrm{C}$ for $4 \mathrm{~h}$.

\subsection{Waveguide characterization}

\subsubsection{Slab waveguide characterization}

In order to correlate the concentration of the $\mathrm{N}-\mathrm{H}$ bonds with the optical propagation loss $\mathrm{SiON}$ slab waveguides are investigated. Among the various methods of loss measurement a scanning detector system was used, which was capable of measuring the variation in the power of scattered light from the surface of the waveguide. In this setup anyone of the guided modes could be excited by making use of a prism coupler [28]. For this purpose a LaSF prism with $n_{\mathrm{TE}}=n_{\mathrm{TM}}=1.875$ was used to excite the fundamental mode in the silicon oxynitride slab waveguides at $\lambda=1.53 \mu \mathrm{m}$. An InGaAs photodetector was used to trace power of the scattered light.

In order to characterize the propagation loss, a study on five samples with the following annealing conditions was performed: sample 1 -as-deposited; sample 2-800 ${ }^{\circ} \mathrm{C}$ for $2 \mathrm{~h}$; sample $3-900{ }^{\circ} \mathrm{C}$ for $2 \mathrm{~h}$; sample $4-1000{ }^{\circ} \mathrm{C}$ 
Table 11

Correlation between the $\mathrm{N}-\mathrm{H}$ bond concentration and the loss profile of the SiON slab waveguides

\begin{tabular}{lll}
\hline $\begin{array}{l}\text { Annealing temperature } \\
\left({ }^{\circ} \mathrm{C}\right)\end{array}$ & $\begin{array}{l}\text { Propagation loss } \\
(\mathrm{dB} / \mathrm{cm})\end{array}$ & $\begin{array}{l}{[\mathrm{N}-\mathrm{H}]} \\
\left(\times 10^{21} \mathrm{~cm}^{-3}\right)\end{array}$ \\
\hline As-deposited & - & 5.2 \\
800 & $3.7 \pm 0.4$ & 2.0 \\
900 & $1.5 \pm 0.3$ & 0.9 \\
1000 & $0.9 \pm 0.1$ & - \\
$1150(4 \mathrm{~h})$ & $<0.2^{\mathrm{a}}$ & - \\
\hline
\end{tabular}

${ }^{\mathrm{a}}$ Estimated.

for $2 \mathrm{~h}$; sample $5-1150{ }^{\circ} \mathrm{C}$ for $2 \mathrm{~h}$. The samples were deposited with identical parameters as the sample sion2 of Section 3.2.1, i.e. $\mathrm{N}_{2} \mathrm{O}$ and $\mathrm{NH}_{3}$ flow of 225 and 15 $\mathrm{sccm}$, respectively. The guiding film thicknesses were about $2.5 \mu \mathrm{m}$ on thermally grown silicon oxide cladding layer of $7.2 \mu \mathrm{m}$ thickness on top of silicon substrate. The propagation loss results, together with their estimated $\mathrm{N}-\mathrm{H}$ bond concentration are given in Table 11.

Accuracy of the measurements was estimated using the standard deviation of the scattered power detected during a scan on a specific sample. The loss result for the as-deposited sample could not be measured, which we account for the presence of large number of scattering centers or voids in the film. The quality of the SiON layers improves with annealing at higher temperatures, as was shown by the FTIR analysis and which is further confirmed with the loss measurements. A steady decrease in the propagation loss for the SiON layers with the corresponding decrease in their $\mathrm{N}-\mathrm{H}$ bond concentration was observed. Namely, the optical loss and $\mathrm{N}-\mathrm{H}$ bond concentration ratio for the samples annealed at 800 and $900{ }^{\circ} \mathrm{C}$ are 2.5 and 2.2 , respectively and are in a good agreement. Furthermore, an additional decrease in the loss is observed after an annealing at $1000{ }^{\circ} \mathrm{C}$. This indicative of a decrease in the $\mathrm{N}-\mathrm{H}$ bond concentration. Finally, the propagation loss for the samples annealed at $1150{ }^{\circ} \mathrm{C}$ was below the detection limits of the system.

\subsubsection{Ridge waveguide characterization}

Having optimized the propagation losses of silicon oxynitride slab waveguides, fabrication and characterization of low loss ridge waveguides utilizing the same material technology was performed. Many applications in optical integrated circuits require two dimensional optical confinement that is achieved by making use of, for example, ridge waveguides. SiON based symmetric ridge waveguides were fabricated with the bottom cladding of $7.2 \mu \mathrm{m} \mathrm{SiO}_{2}, 5 \mu \mathrm{m} \mathrm{SiO}_{x}$ upper cladding, SiON core layer of $0.9 \mu \mathrm{m}$ with rib height and width of 1.1 and $3.0 \mu \mathrm{m}$, respectively. This geometry with core layer index of $n=1.50$ ensures a single mode structure at $\lambda=1.55 \mu \mathrm{m}$, as verified by effective index method and beam propagation method calculations [29]. The core layer of the waveguide was grown identically to the sample sion 2 and was annealed at $1150{ }^{\circ} \mathrm{C}$ for $4 \mathrm{~h}$. The strip of the waveguide was defined by reactive ion etching (RIE) using $\mathrm{CHF}_{3}$ and $\mathrm{O}_{2}$ gases. The strips of the waveguides were defined so as to have some degree of inclination. The driving reason behind this was to minimize the problem of step coverage, during the final step of PECVD deposition of the upper cladding $\mathrm{SiO}_{x}$ layer. An SEM photograph of the ridge structure is given in Fig. 12(a).

The loss characteristics of the ridge waveguides were analyzed by butt-coupling method. Light of $\lambda=1.55 \mu \mathrm{m}$ was coupled into the waveguide by a single mode fiber and collected by a lens directing the light into a $\mathrm{Ge}$ photodetector in either TE or TM polarizations. Applying the cut-back method, insertion loss was measured for identical waveguides of different lengths. The propagation losses of the ridge waveguide were obtained to be

TE : Propagation loss $=0.46 \pm 0.15 \mathrm{~dB} / \mathrm{cm}$,

$\mathrm{TM}$ : Propagation loss $=0.47 \pm 0.17 \mathrm{~dB} / \mathrm{cm}$.

(a)

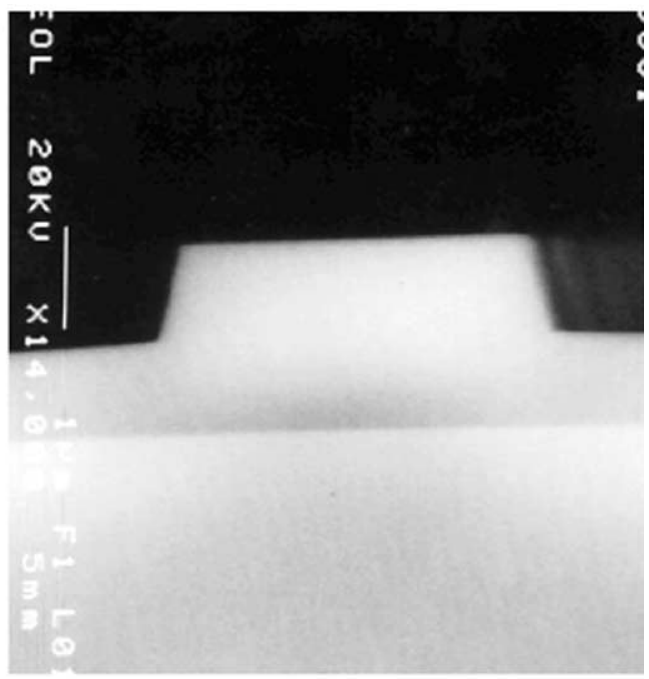

(b)

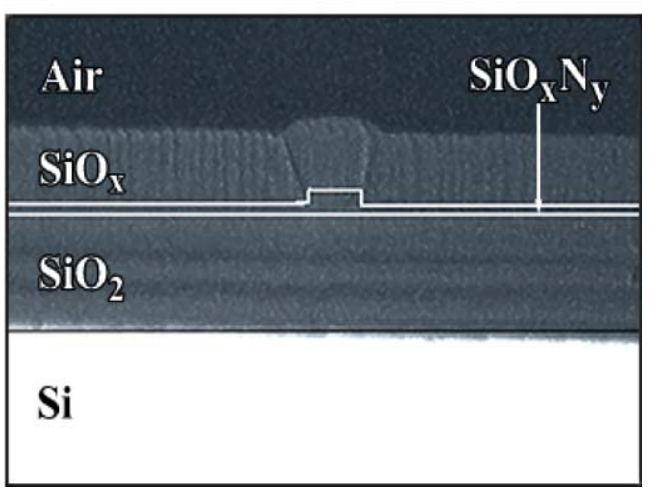

Fig. 12. (a) SEM cross-section photograph of RIE etched rib waveguide structure; (b) optical microscope image of the "discontinuity" formation during growth of the upper $\mathrm{SiO}_{x}$ cladding layer (approximate position of the SiON layer is outlined). 
Analysis of the results leads to the conclusion that the fiber coupling loss is about $4.9 \mathrm{~dB} /$ facet, which points out to the mode profile mismatch and reflection losses at the interface between the guide and fiber. Comparing the propagation losses of the ridge waveguides with the slab guides, we see that former seem to be at least of two times larger. This difference can be attributed mainly to two possibilities. First, after the growth of the upper cladding $\mathrm{SiO}_{x}$ layer the whole structure was not annealed. Evanescent tail of the mode propagating in this layer containing $\mathrm{N}-\mathrm{H}$ bonds contributed to the excess loss. As an example, consider the $\mathrm{TM}_{0}$ mode whose mode profile is wider than that of $\mathrm{TE}_{0}$. Since it propagates with a larger cross section into the upper $\mathrm{SiO}_{x}$ layer its loss is expected and is slightly larger than that of the TE mode. However, the contribution of the upper $\mathrm{SiO}_{x}$ layer is small because only a small fraction of the total power travels in that layer. The major cause of the excess loss in the ridge waveguide, on the other hand, is due to scattering at the sidewalls and discontinuity regions due to the poor coverage, of the upper cladding layer along the ridge edge of the waveguides (Fig. 12(b)). This nonuniformity in the upper cladding should act as scattering interface, thus is expected to make significant contribution to excess loss.

Most recent reports on $\mathrm{SiON}$ ridge waveguides show propagation losses of $\sim 0.1 \mathrm{~dB} / \mathrm{cm}[30,31]$. Both loss values measured in the slab and ridge waveguides reported in this work follow the same trend. The apparent excess loss values in the ridge waveguides can be further decreased, by eliminating the sources mentioned above.

\section{Conclusions}

Silicon oxide, nitride, and oxynitride layers were grown by standard PECVD technique by varying the flow rates of $\mathrm{N}_{2} \mathrm{O}$ and $\mathrm{NH}_{3}$ precursor gases and keeping that of $2 \% \mathrm{SiH}_{4} / \mathrm{N}_{2}$ constant at $180 \mathrm{sccm}$. The refractive index of the layers could be varied between 1.93 and 1.47 by changing the flow rates of the precursor gases.

The compositional properties of these three types of films were investigated via Fourier transform infrared transmission spectroscopy. Special attention was given to the absorption band of $\mathrm{N}-\mathrm{H}$ bond stretching vibration, since its first overtone is known to be the main cause of the optical absorption at $1.55 \mu \mathrm{m}$ wavelength. For silicon oxide films its concentration was found to vary between $7.4 \times 10^{21}$ and $0.4 \times 10^{21} \mathrm{~cm}^{-3}$, while this bond variation for silicon nitride layers was between $9.6 \times 10^{22}$ and $7.9 \times 10^{22} \mathrm{~cm}^{-3}$. For the investigated silicon oxynitride films the corresponding variation of the $\mathrm{N}-\mathrm{H}$ bond was observed to be $0.6-1.7 \times 10^{22} \mathrm{~cm}^{-3}$. Using the results for refractive index and compositional characterization, a silicon oxynitride film with $n=1.50$ was chosen as a material to be used for core layer in single mode optical waveguide fabrication. The next concern was to reduce or eliminate the $\mathrm{N}-\mathrm{H}$ related bond from the this material, an annealing study was performed using a furnace whose temperature profile could be controlled. Several annealing treatments were done at $800,900,1000$, and $1100{ }^{\circ} \mathrm{C}$. As a result, it was possible to reduce the $\mathrm{N}-\mathrm{H}$ stretching bond concentration from $5.2 \times 10^{21} \mathrm{~cm}^{-3}$ to a value $<0.5 \times 10^{21} \mathrm{~cm}^{-3}$, which is below the detection limits of the FTIR transmittance measurements. In order to further verify the absence of $\mathrm{N}-\mathrm{H}$ bonds in the films, an attenuated total reflectance (ATR) Fourier transform infrared technique was employed and the detection limit was further lowered.

Furthermore, applying the same annealing treatment series as for the FTIR characterization, the correlation between the $\mathrm{N}-\mathrm{H}$ bond concentration and the optical propagation loss was demonstrated for planar waveguides. By using prism coupling method and tracing the scattered light with a photodetector low loss slab waveguides were demonstrated. Finally, single mode ridge waveguides were fabricated. the fiber coupling loss measured to be about $4.9 \mathrm{~dB} /$ facet, and the propagation loss was at the order of $0.5 \mathrm{~dB} / \mathrm{cm}$. The poor step coverage, and inclusion of some amount of $\mathrm{N}-\mathrm{H}$ bonds in the upper cladding $\mathrm{SiO}_{x}$ layer, together with the wall roughness of the etched rib were identified as the possible sources of the existing propagation losses which can be further reduced.

\section{Acknowledgements}

We wish to thank Dr. G.L. Bona (IBM Zurich Research Labs), Dr. A. Driessen and C. Roeloffzen (University of Twente, The Netherlands) and I. Kiyat (Bilkent University) for the useful discussions and help with the loss measurements. This work was supported, in part, by Bilkent University Research Fund (Code: Phys-03-02) and The Scientific and Technical Research Council of Turkey (TUBITAK, project no. 199E006).

\section{References}

[1] T. Baak, Appl. Opt. 21 (1982) 1069.

[2] H.P. Zappe, Introduction to Semiconductor Integrated Optics, Artech House, Boston, 1995.

[3] M. Kawachi, Opt. Quant. Electron. 22 (1990) 391.

[4] N. Hatzopoulos, D.I. Siapkas, P.L.F. Hemment, W. Skorupa, J. Appl. Phys. 80 (1996) 4960.

[5] M.C. Netti, M.D.B. Charlton, G.J. Parker, J.J. Baumberg, Appl. Phys. Lett. 76 (2000) 991.

[6] M.J. Rand, R.D. Standley, Appl. Opt. 11 (1972) 2482.

[7] K.E. Mattsson, J. Appl. Phys. 77 (1995) 6616.

[8] R.M. de Ridder, K. Wörhoff, A. Driessen, P.V. Lambeck, H. Albers, IEEE J. Selec. Top. Quant. Electron. 4 (1998) 930.

[9] K. Wörhoff, P.V. Lambeck, A. Driessen, J. Lightwave Technol. 17 (1999) 1401. 
[10] B.S. Sahu, O.P. Agnihotri, S.C. Jain, R. Mertens, I. Kato, Semicond. Sci. Technol. 15 (2000) L11.

[11] M.K. Gunde, M. Maček, Appl. Phys. A 74 (2002) 181.

[12] W.L. Scopel, M.C.A. Fantini, M.I. Alayo, I. Pereyra, Thin Solid Films 425 (2003) 275.

[13] M.L. Hitchman, K.F. Jensen, Chemical Vapor Deposition: Principles and Applications, Academic Press, London, 1993.

[14] A. Sassella, A. Borghesi, F. Corni, A. Monelli, G. Ottaviani, R. Tonini, B. Pivac, M. Bacchetta, L. Zanotti, J. Vac. Sci. Technol. A 15 (1997) 377.

[15] D.V. Tsu, G. Lucovsky, B.N. Davidson, Phys. Rev. B 40 (1989) 1795.

[16] P.K. Bhan, R. Ashokan, J. Appl. Phys. 71 (1992) 2387.

[17] D.M. Wolfe, B.J. Hinds, F. Wang, G. Lucovsky, B.L. Ward, M. $\mathrm{Xu}$, R.J. Nemanich, D.M. Maher, J. Vac. Sci. Technol. A 17 (1999) 2170.

[18] W.A. Lanford, M.J. Rand, J. Appl. Phys. 49 (1978) 2473.

[19] H.G. Tomkins, R.B. Gregory, P.B. Gregory, P.W. Deal, S.M. Smith, J. Vac. Sci. Technol. A 17 (1999) 391.

[20] J.C. Rostaing, Y. Cross, S.C. Gujrathi, S. Poulain, J. NonCrystalline Solids 97-98 (1987) 1051.
[21] Z. Yin, F.W. Smith, Phys. Rev. B 42 (1990) 3666.

[22] Y. Nagasawa, I. Yoshii, K. Narake, K. Yamamoto, H. Ishida, A. Ishitani, J. Appl. Phys. 68 (1990) 1429.

[23] C.M.M. Denisse, K.Z. Troost, F.H.P.M. Habraken, W.F. van der Weg, J. Appl. Phys. 60 (1986) 2543.

[24] K.B. Koller, W.A. Schmidt, J.E. Butler, J. Appl. Phys. 64 (1988) 4704.

[25] A. Fejfar, J. Zemek, M. Trchova, Appl. Phys. Lett. 67 (1995) 3269.

[26] D. Schalch, A. Scharmann, R. Wolfrat, Thin Solid Films 155 (1987) 301.

[27] D.V. Tsu, G. Lucovsky, M.J. Mantini, Phys. Rev. B 33 (1986) 7069.

[28] P.K. Tien, Appl. Opt. 10 (1971) 2395.

[29] C.P. Pollock, Fundamentals of Optoelectronics, Irwin, Chicago, 1995.

[30] T. Shimoda, K. Suzuki, S. Takaesu, A. Furukawa, Proc. of the 28th European Conference on Optical Communication (ECOC 2002), Copenhagen Denmark, paper 4.2.2.

[31] G.-L. Bona, R. Germann, B.J. Offrein, IBM J. Res. Dev. 47 (2003) 239. 